\title{
On Cultivation Measures of Cross-Culture Communicative Competence in English Teaching under the Background of "Chinese Culture Going Out"
}

\author{
Ming Zhao \\ College of Foreign Languages, Bohai University, Jinzhou 121013, China
}

Keywords: Chinese culture going out; English teaching; Cross-culture communicative competence

\begin{abstract}
Under the background of "Chinese culture going out", the cultivation of cross-culture communicative competence has gradually become the focus of college English teaching, and the results have no longer been given priority. The change of teaching ideas requires teachers to appropriately readjust the classroom teaching for better teaching effect with students' interest as the starting point. This paper expounds in detail the specific cultivation measures of cross-culture communicative competence in English teaching.

Preface. At the present, the effect of the cultivation for cross-culture communicative competence in college English teaching is not very good. In response to this, teachers should emphasize the reconstruction of cultural schemas and change the traditional teaching mode in English class. In addition, teachers should also create more opportunities of cross-culture communication for students with students' cross-culture awareness as the starting point to provide students with good exercises and develop their good cross-culture communicative competence.
\end{abstract}

\section{Concept of Cross-Culture Communicative Competence}

Cross-culture communication refers to the processes of language communication and nonverbal communication carried out by individuals of different cultures. Cross-culture nonverbal communicative competence refers to the ability of speakers with cultural identities to appropriately communicate with others. Based on the background of "Chinese culture going out", it can not only enable students to actively perform cross-cultural learning behavior, but also better meet the development needs of knowledge information globalization to cultivate contemporary college students' cross-culture communicative competence in English teaching. In addition, it is more conductive to students' English learning to cultivate students' cross-culture communicative competence, because the same language may have different explanations under different cultural backgrounds. For example, 666 represents auspiciousness in China. But it represents the resurrection day of the devil of Christianity abroad. Only having the ability to communicate cross-culturally, can one better learn and use English language. In a word, under the background of "Chinese culture going out", it has importance significance for English teaching to cultivate students' cross-culture communicative competence, and the two complement each other. Teachers should positively explore some feasible cultivation measures for cross-culture communicative competence for students' English learning.

\section{Cultivation Measures of Cross-Culture Communicative Competence in English Teaching Based on the Background of "Chinese Culture Going Out"}

Restructuring Cultural Schemas. In many cases, English words and Chinese words are not in one-to-one relationship. Therefore, teachers should help students to reconstruct cultural schemas according to cultural difference to make them finish the cross-culture communication behavior by using the new cultural schemas. For example, in accordance with the differences between China and western countries such as historical background, social values and social customs and habits, from the point of view of the differences in culture between vocabulary of the English language and Chinese language, a teacher introduced some common vocabularies with differences in daily communication to students in college English teaching class. In China, the dragon in the idiom 
"hope one's children will be a dragon (will be successful)" represents the rights and status. But in western countries, dragon represents a monster which can breathe fire as a symbol of evil. Therefore, in cross-cultural communication, the differences of Chinese dragon and dragon must be correctly held. In China, cuckoo lament represents the bleak feeling ${ }^{[1]}$. But in western countries, cuckoo represents foolishness. In China, the unsoiled lotus come out of mud represents honest. But in western countries, lotus mainly represents ease. In China, white represents death and failure in many cases. But in western countries, white represents happiness. White-headed boy is a good example, it is usually translated as favourite. As mentioned, there are many differences of culture between China and western countries, and these differences are the basic units to reflect culture. Therefore, in college English teaching, mastering more vocabulary differences can enable students to correctly use various vocabularies in daily communication and develop the good cross-culture communicative competence.

In cross-culture communication, it will make us hard to communicate with others using the original schemas. Therefore, in college English class, to enrich students' knowledge for cross-culture communication and avoid communication failure, teachers should help students construct a new culture schemas by explaining the vocabulary differences to provide students with the appropriate cross-culture communication behaviors and the best communication state. In addition to the vocabulary differences teaching in culture above, teachers should also emphasize the cultural differences for custom and nonverbal communication behavior to gradually cultivate students' cross-culture awareness and make them quickly adapt to the cross-culture communication environment.

Changing The Traditional Teaching Mode. In college English teaching, to conscientiously implement the strategy of "Chinese culture going out" and improve students' cross-culture communicative competence, teachers should change the traditional teaching mode and create more opportunities of cross-culture communication for students. For example, to train students' cross-culture communicative competence, in college English class, a teacher firstly introduced some works with strong cultural information such as The Bible, Aesop's Fables and The Oxford History of Britain, and asked students to make a speech of 5 minutes after independently choosing their favorite works. During speech, every student needed to prepare some questions based on the content of his/her speech, and asked question in lot to the attentive students to concentrate their attention. The "luck listener" chosen would get a opportunity for oral expression. In addition, through participation of speech activity for classic articles, students not only understood history of Britain and America, but also reconstructed the knowledge of cross-culture communication by reciting the original.

Again, to cultivate students' cross-culture communicative competence, in college English class, a teacher organized a cultural and cooperative teaching activity based on the task-based teaching method. The teacher divided the whole class into learning groups and proposed a hypothesis: "a student studying in America wants to go traveling in Italy. Please help him/her plan the travel strategy which includes booking travel agency, introducing tour, applying for a visa, exchanging foreign currency and selecting travelling ways, and the cultural background is English culture." After task release, the teacher played a video with help of a multimedia teaching tools, and in which, the attractions and interior/outer transportation of Italy are mainly demonstrated ${ }^{[2]}$. Then, all groups began to arrange tasks, collect some materials and adapted the results collected into the communicative context. Lastly, students' cross-culture communicative competence was cultivated through the training of oral communication between members.

From the case above, in the teaching activity of college English, it is more conductive to arouse students' learning interest, develop students' cross-culture communicative competence in a good learning environment to be good at expressing themselves with cross-culture language to replace the traditional teaching mode with the new teaching methods such as speech for classic articles and cultural cooperation.

Emphasizing Cultivation of Cross-Culture Awareness. In college English class, comparative analysis approach can effectively stimulate students' cross-culture awareness to gradually develop 
students' cross-culture communicative competence. For example, in college English class, to strengthen cultivation of students' cross-culture awareness, a teacher leaded students to analyze the customs of wansheng night and yuan festival with the comparative analysis approach for cultural context, and asked students to make comparative analysis for the customs of China and western countries in English. A student said: "Yuan festival to sacrifice ancestors mainly, more solemn solemn, Halloween to joy and lively, entertainment". Student B said: "In China, some places will put river lights on the Chinese yuan festival, while the western wansheng night pays more attention to the preparation of table delicacies, with different customs." In the process of comparative analysis for cultural context, students not only mastered some customs of China and western countries, but also developed their cross-culture awareness and cross-culture communicative competence. Again, in college English class, to activate classroom atmosphere and improve students' cross-culture communicative competence, a teacher firstly played some movie clips with strong customs for wedding or funeral such as Bean and Garfield. Then the teacher leaded students to carry out the group work discussion that students were asked to discuss the ways of people of different nationalities to people in groups. The comparative analysis approach for cultural context is used to discuss the cultural differences between China and western countries in depth to be well prepared for later success in communication.

Again, in college English class, to cultivate students' cross-culture awareness and communicative competence, a teacher changed the traditional and mechanical way of teaching dialogue of 2-3, emphasized the original novels, plays and movies of Britain and America as the teaching materials and leaded students to do some role play. With Four Weddings and a Funeral as an example, the teacher selected the clip after Charles' receiving of the wedding invitation from Kelly. When choosing gift, Charles met Kelly and wanted to propose to Kelly impulsively. Then a student was selected to play Charles, and another student was selected to play Kelly. In addition, several students were supporting roles ${ }^{[3]}$. Then, the teacher distributed the scripts to students and asked them to prepare props by themselves and perform it. This teaching mode can build a relatively relaxed learning environment for students, make them actively learn the skills of cross-culture communication in a good learning environment and develop their cross-culture communication awareness and competence.

From the case above, only after having the awareness of cross-culture communication, students' cross-culture communicative competence can be gradually cultivated. Teachers should emphasize cultivation for students' awareness of cross-culture communication.

Introducing Communication Behaviors of English Speaking Countries. In process of the teaching activity of college English, it is beneficial for cultivation of students' cross-culture communicative competence to introduce some communication behaviors of English speaking countries. For example, in college English teaching, to cultivate students' cross-culture communicative competence, a teacher introduced some communication behaviors of English speaking countries to them. In China, the forms of address in communications such as young\&old, identity and career are relatively emphasized. But in western countries, people are used to calling their relatives by their first names. When talking with non-relatives, people are used to use the forms of address of Mr./Miss/Mrs. In China, the communicative language such as "Where are you going?" are often used to ask someone in daily communication. In western countries, the communicative language such as "How are you?" and "Good morning!" are often used to simply ask someone. In this way, the awkward behaviors such as prying into others' affairs can be avoided. Through introduction of the communication behaviors of English speaking countries, students can master more skills of cross-culture communication in English learning for successful communication. Taking another example, a teacher emphasized the introduction of table manners in English class. For example, in China, people are used to entertain relatives and friends with various delicious food. In western countries, people are used to entertain guests with 6 courses of food.

Language customs differences are the major factors of successful communication. In the teaching activity of college English, teachers should introduce various differential communication behaviors to students to make them really understand the communication customs of English 
speaking countries, build good difference awareness and avoid cultural differences and touching of taboo area of someone in communication. Only in this way, successful cross-culture communication activity can be realized ${ }^{[4]}$. Besides language communication behaviors, in English class, the teacher Haiying introduced some nonverbal communication behaviors of English speaking countries to students such as body language and touching behavior to make students finally realize successful nonverbal communication with ease. In a word, when cultivating students' cross-culture communicative competence, it is very important to introduce some skills of cross-culture communication to students. Teachers should pay more attention to this aspect for better teaching effect.

\section{Conclusion}

In conclusion, in college English teaching, the cultivation for students' cross-culture communicative competence is very important. It can make students the overall quality of talent with knowledge and ability, overcome their nervousness and anxiety in language communication, be not afraid of voicing their points in English in daily communication for successful communication and actively participate in various cross-culture language activities.

\section{References}

[1] Levent Uzun. Utilising Technology for Intercultural Communication in Virtual Environments and the Role of English[J]. Procedia - Social and Behavioral Sciences, 2014, 01: 116.

[2] Alireza Hazrati. Intercultural Communication and Discourse Analysis: The Case of Aviation English[J]. Procedia - Social and Behavioral Sciences, 2015, 06: 192.

[3] Tatiana M. Permyakova. Metaphors of Intercultural Communication in English and Russian Academic Texts[J]. Journal of Intercultural Communication Research, 2015, 44(3): 252-261.

[4] Phyllis Ngai, Sandra Janusch. Intercultural Communication Training for English Language Teachers: A Case Study of an Immersion Program for South Korean Teachers[J]. Journal of Intercultural Communication Research, 2015, 44(4): 345-368.

[5] Peng L. Cost heterogeneity and peak prediction in collective actions [J]. Expert Systems With Applications, 2017, 79: 130-139. 